\title{
Effects of melatonin implants on reproductive seasonality of male red deer (Cervus elaphus)
}

\author{
J. R. Webster*, J. M. Suttie† and I. D. Corson \\ MAF Technology, Invermay Agricultural Centre, Private Bag, Mosgiel, New Zealand
}

\begin{abstract}
Summary. Red deer stags were treated with melatonin implants in 2 experiments designed to examine the control of reproductive seasonality. In Exp. 1, stags $(n=24)$ were allocated to 4 treatment groups: 2 groups were treated with 3 implants per stag each month from 8 November to 5 February (EM) or 9 December to 5 February (LM), 1 untreated group of control stags remained with the melatonin-treated stags (CC) and the other untreated control group remained isolated (IC). Melatonin treatment advanced the seasonal changes in scrotal circumference, liveweight, antler state and coat type compared with control stags. The extent of advancement was greater in EM than LM stags. In EM and LM stags, size of testes regressed rapidly and antlers were cast shortly after melatonin implants became exhausted in March. This was followed by an additional antler cycle and reproductive development and decline from June to November. EM and LM stags became synchronized with control stags 14-15 months after melatonin treatment began. The extra cycle of seasonal changes was more pronounced in EM than in LM stags. In Exp. 2, stags $(n=30)$ were allocated to 6 treatment groups: 4 groups were treated with 3 implants per stag at monthly intervals for 6 months from 22 June (J), 4 August (A), 16 September (S) and 23 October (O), a further group of stags was treated in the same manner for 12 months from $22 \mathrm{June}(\mathrm{Y})$, and the remaining group was untreated $(\mathrm{C})$. Compared with control stags, testicular regression and antler casting was delayed in Groups $J$, A and Y. These events occurred at the same time as in control stags in Groups $S$ and $O$. Subsequent reproductive development was advanced in Groups $\mathrm{S}$ and $\mathrm{O}$ and delayed in Groups $\mathbf{J}, \mathrm{A}$ and $\mathrm{Y}$. The results demonstrated that treatment with melatonin implants in November or December advanced reproductive development. However, when stags were treated with melatonin implants from June to August, reproductive development was delayed, indicating a change in response to melatonin treatment during the year. The change in response to melatonin treatment between late winter and early spring was interpreted as a resetting of an endogenous circannual rhythm caused by a photoperiodic cue responsible for initiating the final stages of reproductive regression.
\end{abstract}

Key'w'ords: red deer; melatonin; reproduction; antlers

\section{Introduction}

Red deer are a highly seasonal species and stags undergo a pronounced annual reproductive cycle, alternating between infertility during late winter and spring, and peak reproductive condition during late summer and autumn (Lincoln, 1971). Studies on another seasonally breeding ungulate, sheep, have demonstrated that annual reproductive cycles are the result of an endogenous rhythm

*Present address: Reproductive Sciences Program, University of Michigan, 300 N Ingalls Building, 11th Floor, Ann Arbor, MI 48109-0404, USA.

†Reprint requests. 
which is entrained with the seasons by the annual cycle of photoperiod (Karsch \& Wayne, 1988). The effects of photoperiod on reproduction are mediated by melatonin, which is secreted by the pineal gland during darkness (Kennaway et al., 1982; Bittman et al., 1983). The resulting hormonal code for light and dark conveys photoperiodic information which entrains seasonality. In red deer stags, the involvement of photoperiod and the pineal gland in entraining seasonality is indicated by the altered timing of annual cycles produced by artificial manipulations of the daily photoperiod (Jaczewski, 1954; Pollock, 1975; Suttie et al., 1984) and treatment with melatonin implants (Lincoln et al., 1984; Bubenik \& Smith, 1987). However, endogenous circannual rhythms under constant photoperiodic conditions or after physical disruption of photoreceptive processes have not been studied in red deer stags. For example, normal annual antler and reproductive cycles persisted in red deer stags after pineal denervation (superior cervical ganglionectomy), but these stags were shown to be responsive to artificial photoperiodic manipulations (Lincoln, 1985).

Treatment of red deer stags with melatonin implants during early summer advanced seasonal reproductive development (Lincoln et al., 1984), an effect similar to that expected if the stags had been exposed to a reduction in photoperiod length. Melatonin implants therefore represent a convenient method of inducing a reaction to a change in photoperiod length, although the photoperiodic signal that melatonin implants actually represent, if any, is unknown.

The aim of the present experiments was to perturb seasonal growth and reproductive cycles in red deer stags, using melatonin implants, and to study the changes in the rhythms of scrotal circumference, liveweight and antlers which were consequences of this perturbation.

\section{Materials and Methods}

Preliminary experiment. Five adult red deer stags were treated with 3 subcutaneous melatonin implants (18 mg melatonin in a 4- $\mathrm{mm}^{3}$ coated pellet implant; Regulin Ltd, Melbourne, Victoria, Australia) positioned with a trochar under local anaesthesia (xylocaine; Bayer NZ Ltd, Petone, NZ). They were blood sampled 7 days before implanting (at midday and midnight), on the day of implanting and at intervals for 112 days after implanting. In addition, 45 adult stags were blood sampled once at midday. All samples were analysed for plasma melatonin.

Experiment 1. This experiment was designed to determine whether melatonin implants in early summer could advance the onset of the breeding season and if so what were the longer term consequences of treatment.

Seven-year-old stags $(n=24)$ were randomly allocated to 4 groups of 6 animals each and were kept outside on pasture under natural photoperiodic conditions at $45^{\circ} \mathrm{S}$ in New Zealand.

Stags were each treated with 3 subcutaneous melatonin implants at approximately monthly intervals. One group began treatment on 8 November (early melatonin, EM) and another group on 9 December (late melatonin, LM). The final treatment date for both groups was 5 February. One group of untreated control stags remained with the treated stags (contiguous control, CC) and the other control group was isolated until 3 months after the final implantation date (isolated control, IC).

All measurements except liveweight were taken from every animal under general anaesthesia. at the beginning of each month from November 1985 until March 1987. Liveweight was determined before anaesthesia each month. Scrotal circumference was measured around the widest part of the scrotum using a flexible plastic tape measure. Antler state (i.e. velvet or hard) was recorded. Casting date, if not observed, was estimated from the extent of wound healing and from measurements of velvet antler length based on criteria from earlier studies (J. M. Suttie \& I. D. Corson, unpublished). Coat type (winter, summer or moulting) was assessed visually according to the descriptions of Ryder \& Kay (1973).

Stags were anaesthetized with xylazine hydrochloride (Rompun: Bayer, NZ Ltd. Petone, NZ) at a dose rate of $1.0 \mathrm{mg} / \mathrm{kg}$ liveweight and fentanyl citrate (Fentaz), $10 \mathrm{mg} / \mathrm{ml}$, and azaperone, $80 \mathrm{mg} / \mathrm{ml}$ (Janssen Pharmaceutica, Beerse, Belgium) at a dose rate of $0.002 \mathrm{ml} / \mathrm{kg}$ liveweight. Reversal of sedation was achieved using yohimbine hydrochloride (Sigma, St Louis, MO, USA) at a dose rate of $0.25 \mathrm{mg} / \mathrm{kg}$ liveweight and nalorphine (Lethidrone: Wellcome, $\mathrm{UK}$ ) at a dose rate of $5 \mathrm{mg} / \mathrm{stag}$.

Experiment 2. This experiment was carried out to determine how early in the spring melatonin treatment could be carried out to advance the onset of the breeding season.

Four-year-old stags $(n=30)$ were allocated to 6 equally sized groups and kept together outside on pasture under natural photoperiodic conditions.

Stags were each treated with 3 melatonin implants per month for 6 consecutive months beginning on 22 June, i.e. winter solstice (J), 4 August (A), 16 September (S) and 23 October (O). A further group of stags was treated with 3 melatonin implants per month for 12 consecutive months beginning on 22 June (Y) and the remaining group was untreated $(\mathrm{C})$. 
Towards the end of each month between June 1987 and June 1988 the stags were weighed and anaesthetized with xylazine hydrochloride at a dose rate of $1.0 \mathrm{mg} / \mathrm{kg}$. Liveweight and scrotal circumference, and antler status were recorded as in Exp. 1. Sedation was reversed using yohimbine hydrochloride at a dose rate of $0.25 \mathrm{mg} / \mathrm{kg}$. Liveweight antler status was monitored until January 1989.

Melatonin assay. Plasma concentrations of melatonin were measured in duplicate by Dr D. J. Kennaway using radioimmunoassay as previously described (Kennaway et al., 1982). Assay sensitivity was $155 \mathrm{pmol} / \mathrm{l}$ with an intraassay coefficient of variation of $<6 \%$ for control plasma pools of 354 and $2099 \mathrm{fmol} /$ tube. Interassay coefficients of variation were $6.5 \%$ at $120 \mathrm{fmol} /$ tube $(22.4 \% \mathrm{~B} / \mathrm{Bo})$. The $50 \%$ binding point was at $347 \mathrm{fmol} /$ tube.

Statistical analysis. For each monthly sampling date and for appropriate differences between months, variables were analysed by univariate analysis of variance over treatment groups. Following a significant F-test, comparisons between the treatment groups were made using the $t$ test. Significance levels on the figures are those from the analysis of variance and indicate a difference between treatments. Significance levels in the text are those from the $t$ test and indicate differences between specific treatment groups.

During Exp. 1, 4 animals died from inhalation pneumonia and 1 from heat stress (Fig. 3) and their data remained in the analysis until the time of death. During Exp. 2, 4 stags died from causes unrelated to treatment (all inhalation pneumonia) but their data remained in the analysis until the time of death (Fig. 5).

\section{Results}

\section{Preliminary experiment}

The mean ( \pm s.e.m.) plasma melatonin concentration of all samples taken during the daytime from untreated stags $(n=45)$ was $158.9 \pm 12.9 \mathrm{pmol} / 1$ (Fig. 1). The mean preimplantation nocturnal melatonin concentration from the 5 stags which received melatonin implants was $636 \pm 95 \cdot 1 \mathrm{pmol} / \mathrm{l}$. Daytime plasma melatonin values increased after implantation to be above normal nocturnal concentrations after 10 days and remained above this level until 29 days after implantation, when the highest melatonin concentration of $1436 \pm 481 \mathrm{pmol} / 1$ was recorded. Melatonin concentrations had dropped below normal nocturnal values by 43 days after implantation, but remained above normal daytime levels until 78 days after implant insertion.

\section{Experiment 1: effects of treatment with melatonin implants from November or December until March}

Scrotal circumference. There was no evidence of any differences between Groups CC and IC at any time. The seasonal increase in scrotal circumference was accelerated in Group EM stags (Fig. 2) and mean scrotal circumference was larger in stags in Group EM than in Groups LM, CC and IC in December $(P<0.05)$. Development of the testes was also stimulated in Group LM stags and by January the mean scrotal circumference of stags in Groups EM and LM was larger than that of both groups of control stags $(P<0.05)$. Scrotal circumference reached a maximum for Group EM stags in January, for Group LM stags 1 month later in February and in both groups of control stags 1 month later in March. The scrotal circumference of the melatonin-treated stags began to decline at a more rapid rate than did that of control stags from April to June and was less than that of stags in both control groups in June $(P<0.01)$. After reaching a minimum in June, the testes of the melatonin-treated stags underwent an extra cycle of development and regression from August to November. The increase in testes size was larger and more prolonged in Group EM stags than in Group LM stags. Subsequently, the mean scrotal circumference of stags in Group EM was larger than that of control stags in August $(P<0.05)$, September $(P<0.001)$, October $(P<0.01)$ and November $(P<0.05)$ and larger than that of stags in Group LM in September and October $(P<0.01)$. The mean scrotal circumference of $\mathrm{LM}$ stags was greater than that of control stags in August $(P<0.05)$ and September $(P<0.001)$ only. All groups had similar values for scrotal circumference over the subsequent January to March.

Liveweight. A dramatic loss of weight occurred in both groups of melatonin-treated stags in late January, 2 months earlier than in control stags (Fig. 2) and the mean liveweight of stags in Groups 


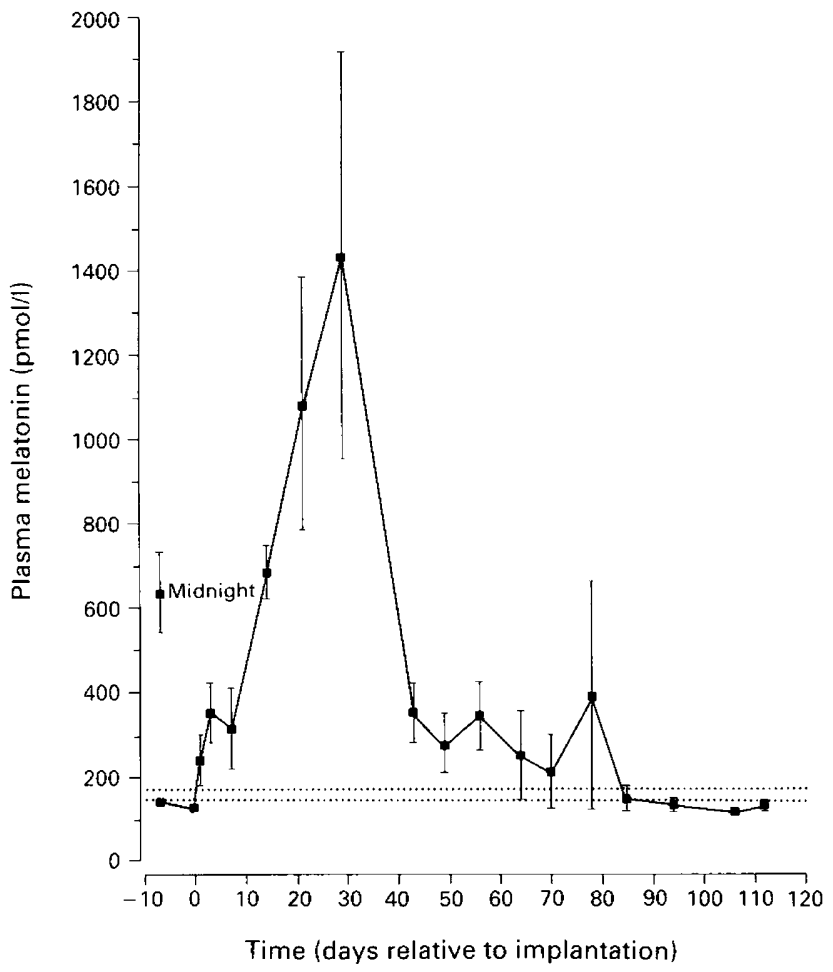

Fig. 1. Mean \pm s.e.m. plasma melatonin concentration in red deer stags $(n=5)$ before and after insertion of 3 melatonin implants each. At 7 days before implant insertion each stag was bled at midday and midnight. The broken lines represent the mean \pm s.e.m. of daytime melatonin concentrations of 45 stags blood sampled on one occasion.

EM and LM was lower than that of the control stags in February $(P<0.01)$. Melatonin-treated stags gained weight over the winter period of April to October $(P<0.05)$; in contrast, the control stags did not increase in weight $(P>0 \cdot 05)$. The winter increase in liveweight was more pronounced in Group EM stags which were heavier than control stags in August and heavier than control and Group LM stags in September $(P<0.05)$.

Antler cycle. The mean cleaning date for stags treated with melatonin from November to 17 January was 25 days (s.e.d. $=4.98)$ earlier than the mean of the other groups $(P<0.05)$ (Fig. 3 ). There was no significant difference in the time antler cleaning took place between Group LM and control stags $(P>0.05)$. Stags in both melatonin-treated groups cast their antlers during April-May $(E M=7$ May, $\mathrm{LM}=8$ May; s.e.m. $=4.7$ days $)$ and grew an extra set of antlers during the winter. The mean casting date of Group EM stags was 10 October, significantly later $(P<0 \cdot 05)$ than for Group LM stags (11 September). The mean antler casting dates for stags in Groups CC and IC were 19 August and 27 August, respectively. The pooled s.e.d. for all casting dates for stags in spring (Groups EM, LM, CC and IC) was 6.2 days. Thereafter all stags grew antlers from September to February and cleaned them about the same time the following February to March (Fig. 3).

Coat. Stags in Groups EM and LM began to moult their summer coat and grow a winter coat earlier than did control stags (Fig. 3). The melatonin-treated stags moulted this winter coat and grew a summer coat in mid-winter, then moulted this coat to grow another winter coat. At this stage the melatonin-treated stags were growing a winter coat while the control stags were moulting a winter coat. The melatonin-treated stags moulted this second winter coat in spring and grew a summer coat and became synchronized with control stags. 

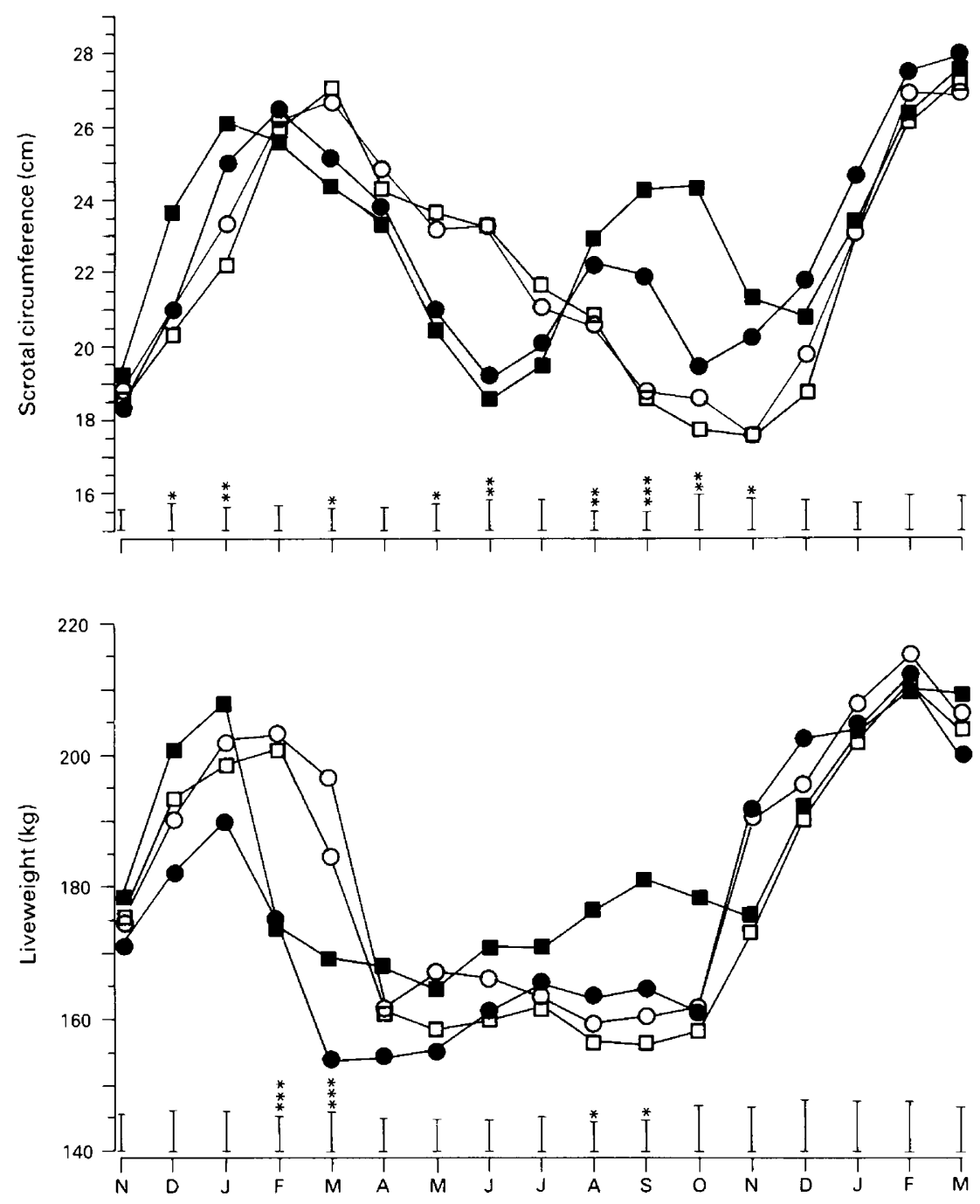

Fig. 2. Scrotal circumference and liveweight in stags in Groups EM (ם), LM (๑), CC ( $\square)$ and IC $(O)$ in Exp. 1, for each month of the study. The vertical bars represent the pooled s.e.m. for each month and significance levels for differences between treatments (ANOVA) are indicated: ${ }^{*} P<0.05,{ }^{* *} P<0.01,{ }^{* * *} P<0.001$.

Experiment 2: effects of treatment with melatonin implants beginning in winter and spring (June to October) or for a full year

Scrotal circumference. The mean scrotal circumference in Groups C, S and O decreased during winter, reaching a minimum for Groups $\mathrm{C}$ and $\mathrm{S}$ in October and Group $\mathrm{O}$ in November (Fig. 4). This decrease was delayed in Groups $\mathrm{Y}, \mathrm{J}$ and $\mathrm{A}$ and subsequently the mean scrotal circumference of these groups was larger than those of stags in Groups $\mathrm{S}, \mathrm{O}$ and $\mathrm{C}$ in September $(P<0.05)$ and October $(P<0.01)$. The minimum scrotal circumferences of stags in Groups $\mathrm{Y}, \mathrm{J}$ and $\mathrm{A}$ was recorded in December, 2 months later than that of Group $C$ stags. The delayed testicular development in Groups $Y, J$ and $A$ resulted in a smaller scrotal circumference in these 3 groups than in Groups S, $\mathrm{O}$ and $\mathrm{C}$ in December, January and February $(P<0 \cdot 01)$. Between February and March the mean scrotal circumference of stags in Groups $S, O$ and $C$ decreased by $1.1 \mathrm{~cm}$, while that of 


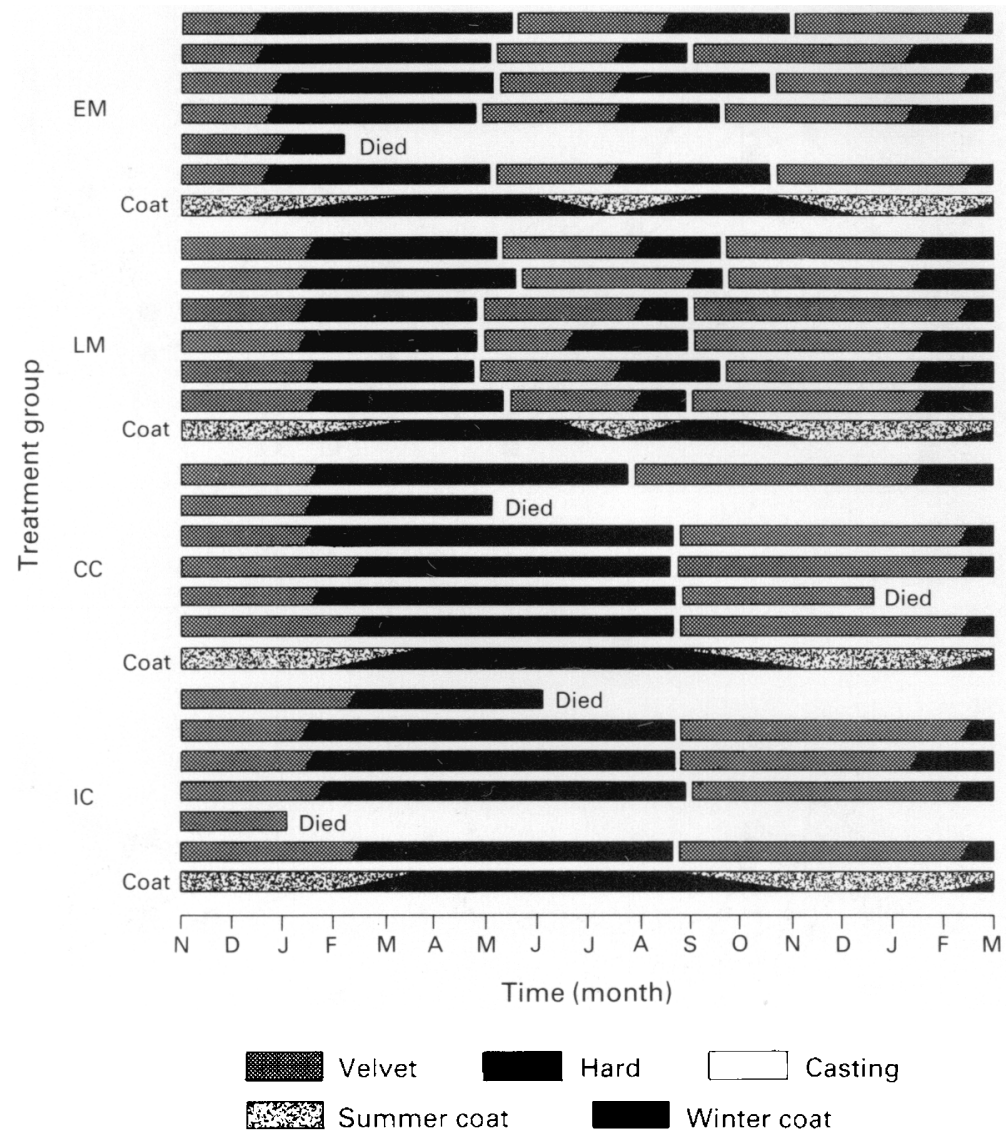

Fig. 3. Diagrammatic representation of antler cycles of individual stags in the 4 groups in Exp. 1 and mean coat type (proportion with summer or winter coat) for each treatment group. Dates when stags died are also shown. Antler cleaning occurred between the velvet and hard antler stages.

Groups $\mathrm{Y}, \mathrm{J}$ and $\mathrm{A}$ increased by 2.1 (s.e.d. $=0.81$ ) $\mathrm{cm}$. By April the mean scrotal circumference of stags in Groups Y, $\mathbf{J}$ and $\mathrm{A}$ was larger than that of stags in Groups $\mathrm{S}, \mathrm{O}$ and $\mathrm{C}(P<0 \cdot 05)$.

Liveweight. The only month when there was a significant difference in liveweight between groups was in February when Groups $\mathbf{J}, \mathrm{A}$ and $\mathrm{O}$ were lighter than control stags $(P<0 \cdot 05)$. There were differences between groups in the pattern of liveweight changes (Fig. 4). The increase in liveweight which occurred in control stags from December to March was delayed and less pronounced in Groups $\mathrm{Y}, \mathrm{J}$ and $\mathrm{A}$, while Groups $\mathrm{S}$ and $\mathrm{O}$ reached a peak in liveweight earlier than control stags.

Antler cycle. Casting was delayed $(P<0.001)$ in Groups $\mathrm{Y}$ (1 November), 2.8 days, J (14 November) and A ( 7 November) compared with Groups S (16 September), O (15 September) and C (18 September) (s.e.d. $=8.5$ days) (Fig. 5). Antler cleaning was advanced in Groups $\mathrm{S}$ and $\mathrm{O}$ (January in all but one of these stags) and delayed in Groups Y, J and A (March) compared with control stags which had their antlers clean of velvet in February. Casting of this set of antlers occurred earlier $(P<0.05)$ in Group S (17 June) than Group O (22 July), which was also earlier $(P<0.05)$ than control stags $(15$ September; s.e.d. $=10 \cdot 2$ days). Casting in Groups Y (1 September), J (23 September) and A (19 September) was not significantly different from that of control stags although one stag in Group A (which was not included in the calculation of casting date in this group) cast on 26 May and underwent an extra cycle of antler growth, casting these antlers on 25 November. 

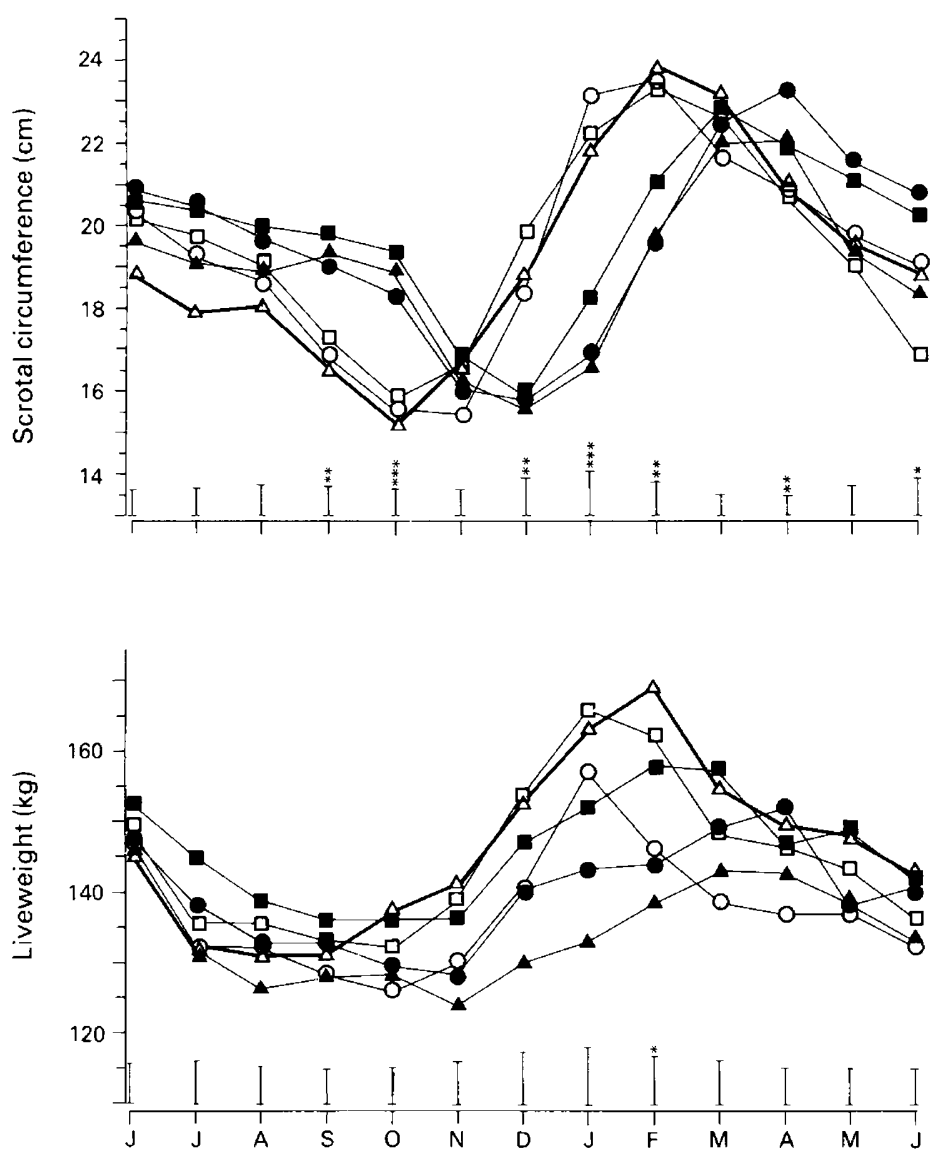

Fig. 4. Scrotal circumference and liveweight in groups treated with melatonin for 6 months beginning in June $(\mathbf{J}, \mathbf{O})$, August $(\mathbf{A}, \mathbf{\Delta})$, September $(\mathbf{S}, \square)$, October $(\mathrm{O}, \mathrm{O})$ or treated with melatonin for 12 months beginning in June $(Y, \boldsymbol{E})$ and control stags untreated with melatonin (C, $\triangle$ ), in Exp. 2. The vertical bars represent the pooled s.e.m. for each month and significance levels for differences between treatments (ANOVA) are indicated: ${ }^{*} P<0.05,{ }^{* *} P<0.01$, *** $P<0.001$.

\section{Discussion}

The melatonin implants maintained daytime plasma concentrations of melatonin above normal daytime levels for 78 days and above nocturnal levels for 35-43 days after implantation. After an initial start-up period of 10-15 days, therefore, melatonin concentrations would most likely have been continuously increased in all stags in both of the experiments until at least 40 days after insertion of the final melatonin implant. The plasma concentrations of melatonin are similar to those reported by Asher et al. (1988) for fallow deer.

The farmed red deer stags in these experiments underwent pronounced annual cycles in many physiological parameters which were similar to those previously reported (Lincoln, 1971). Two groups of control stags were used in Exp. 1 to guard against any pheromonal or physical effects that early rutting stags may have on their untreated counterparts and to investigate whether control animals required to be separated from treated animals in future experiments. This was apparently unnecessary as there were no significant differences between stags in Groups CC and IC at any 


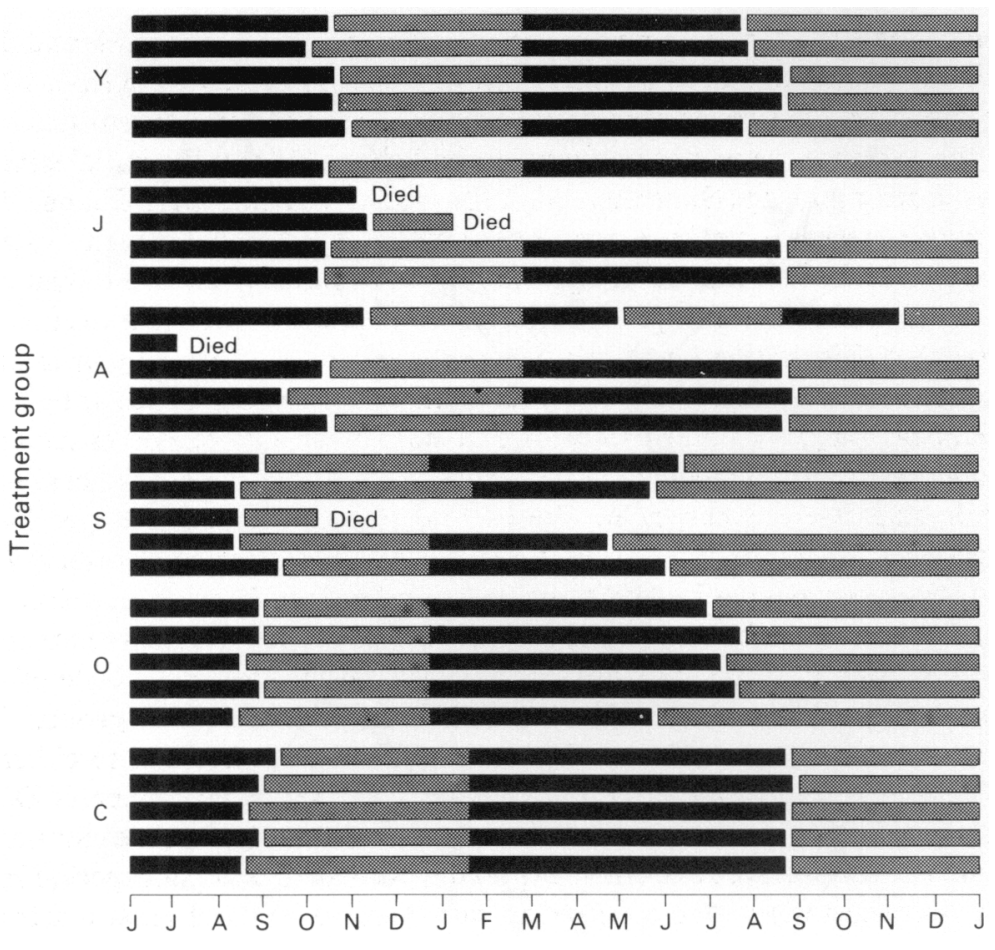

W0lvet $\square$ Hard $\square$ Casting

Fig. 5. Diagrammatic representation of antler cycles of individual animals in Groups Y, J, A, S, $\mathrm{O}$ and $\mathrm{C}$ throughout the study in Exp. 2. Dates when stags died are also shown. Antler cleaning occurred between the velvet and hard antler stages.

stage of the experiment and seasonal reproductive changes in control animals occurred at the expected time for Invermay stags (Fennessy et al., 1988).

Treatment of red deer stags with melatonin implants from November or December until March resulted in primary effects which occurred during the period of treatment and secondary effects which occurred after treatment had ended. The initial effect of treatment with melatonin implants was to accelerate the sequence of changes which occurred in control stags, resulting in an advanced seasonal state, as has been found previously (Lincoln et al., 1984). Testicular development was accelerated by melatonin treatment starting in November and December; the earlier starting date resulted in a greater advancement. Advanced testicular development in melatonin-treated stags was associated with earlier development of secondary sexual characteristics such as antler cleaning. Treatment of red deer stags with melatonin implants by Lincoln et al. (1984) also advanced antler cleaning and was associated with an early increase in blood testosterone concentrations. Melatonin treatment beginning in November advanced the timing of peak seasonal weight gain while treatment in December did not, although both treatments resulted in an early fall in liveweight which began in January. Stags in Groups EM and LM moulted their summer coats earlier, as has also been reported in red deer hinds (Webster \& Barrell, 1985; Barrell \& Staples, 1987) treated with melatonin. This result further supports a role for photoperiod in entrainment of coat growth cycles in red deer (Kay \& Ryder, 1978) and confirms coat type as a useful indicator of an animal's seasonal state. 
The secondary effects of melatonin treatment occurred in Groups EM and LM when the February implants would have become exhausted in March. Before this period, while melatonin treatment was continuing, the testes were decreasing in size in both melatonin-treated groups. This indicated that the response to melatonin treatment had changed from the initial stimulatory effect. Similar changes in red deer stags (Lincoln et al., 1984) and rams (Lincoln \& Ebling, 1985) following implantation of melatonin have been reported. During April and May the rate of testicular regression increased in the EM and LM stags. As treatment starting dates and treatment durations were different between the two groups but the end of melatonin treatment occurred at the same time, it may be that this accelerated testicular regression was a result of melatonin treatment coming to an end. Testicular regression was accompanied by casting of the antlers in April-May and velvet antler began to grow immediately after casting. A second cycle of testicular development and regression occurred during late winter and spring from August to November. This extra cycle took place while stags were experiencing the natural photoperiodic cycle, yet the sequence of physical changes was out of its normal relationship with photoperiod. Furthermore, this extra testicular cycle was accompanied by additional rises and falls in liveweight, velvet antler growth and cleaning and moulting of the winter and summer coats. These cycles were more pronounced in stags in Group EM than in those in Group LM, suggesting that the magnitude of the additional cycle was influenced by differences in melatonin treatment between the two groups. The difference in size of the extra cycles between Groups EM and LM was therefore due to either the duration of treatment (4 months is 3 months) or the onset of treatment (November vs December) or a combination of the two. The occurrence of additional cycles after melatonin treatment has not been previously reported. However, red deer stags exposed to a reduction in photoperiod in spring which advanced antler mineralization were reported to cast these antlers and grow a second set shortly after being returned to the natural photoperiod in summer (Jaczewski, 1954).

Treatment of red deer stags with melatonin implants for 6 months beginning at regular intervals from June to October produced two distinct effects and the treatments can be separated into two groups, those which began before September and those which began in September or later. Melatonin treatment before September (Groups $\mathrm{J}, \mathrm{Y}$ and A) resulted in a delay in reaching the nadir of the annual cycle. Thus minimum testes size and antler casting occurred 2-3 months later than in control stags. This delay resulted in later reactivation of the testes and subsequent development of secondary sexual characteristics. The melatonin-treated stags became synchronized with control stags in August-September when they cast their antlers at the same time as control stags, with the exception of one animal in the group which had grown an additional antler during the previous winter.

Melatonin treatment began in Groups $\mathrm{S}$ and $\mathrm{O}$ at the time of or after casting respectively, and so the date of this event was unaffected. The sequence of changes which occurred in control stags during spring and summer (October-February) tended to be accelerated in the melatonin-treated stags as occurred in Exp. 1. However the differences in testes size and liveweight between Groups $S$ and $\mathrm{O}$ and control stags were not significant. Although a significant advancement of seasonal changes was expected from the results of Lincoln et al. (1984) and Exp. 1, the less pronounced advancement of seasonality by melatonin treatment in the present experiment may be due to stag age. An age-dependent effect of melatonin treatment of red deer stags was found by Fisher et al. (1988), suggesting that younger stags were less responsive to melatonin treatment.

A completely different response occurred between treatment on 4 August which delayed reproductive regression and subsequent redevelopment and treatment on 16 September which advanced reproductive development. One difference between these two dates is that the former was before the final stages of testicular regression and casting and the latter was at casting when the testes were almost maximally regressed. These two events must mark a change in the way in which melatonin treatment is interpreted. It would appear that between 4 August and casting there is a photoperiodic cue responsible for entraining that event. The effect of melatonin implants in June and August was to prevent the stags from perceiving this cue and thus the final stages of testicular 
regression and casting did not occur. After these two events had taken place, reproductive development began, and therefore these two events also mark a change in the underlying direction of seasonal movement.

The stags which were treated with melatonin implants for 1 year (Group Y) exhibited circannual cycles of testes size, liveweight and antlers. This result is consistent with the cyclical changes in testicular activity found in rams during long-term treatment with melatonin (Lincoln \& Ebling, 1985). Although treatment for 12 months was insufficient to calculate the length of these cycles, their presence provides evidence of endogenous circannual rhythmicity in red deer stags. However, the use of other environmental cues to entrain a circannual rhythm cannot be excluded in the present experiment. The second period of casting in Group Y stags occurred at a time similar to that of control stags. As melatonin implants would have become exhausted around the time of the winter solstice (June), Group Y stags would have experienced the same natural photoperiod as control stags from the winter solstice onwards. It is possible that this section of photoperiod may be important in timing antler casting. Further evidence of the importance of this section of the annual photoperiodic cycle in seasonal entrainment is the synchrony of antler casting between Groups $\mathbf{J}$ and $\mathrm{O}$, in which treatment ended in December and February and Group $\mathrm{Y}$ in which treatment did not end until June. This suggests that the natural photoperiod that Groups $J$ and $O$ experienced after the end of treatment did not have a major effect on their seasonality. The only section of natural photoperiod that these 3 groups shared, and which was responsible for their synchrony, was from the winter solstice onwards.

The results are consistent with the view that reproductive seasonality in red deer stags is due to the entrainment of an endogenous circannual rhythm by photoperiod and that this entrainment is mediated via melatonin secretion from the pineal gland. In red deer stags it would appear that the increasing photoperiod in early spring is particularly important in the entrainment process.

We thank B. A. Veenvliet, R. E. Labes and other members of the Deer Group at Invermay Agricultural Centre for assistance in animal handling and data collection; T. M. Manley and G. M. Caughey for help with LH assays; and R. P. Littlejohn for statistical advice.

\section{References}

Asher, G.W., Barrell, G.K., Adam, J.L. \& Staples, L.D. (1988) Effects of subcutaneous melatonin implants on reproductive seasonality of farmed fallow deer (Dama dama). J. Reprod. Fert. 84, 679-691.

Barrell, G.K. \& Staples, L.D. (1987) Melatonin implants alter calving season in farmed red deer. Proc. $17 \mathrm{th}$ Congr. Int. Union of Game Biol. 18.

Bittman, E.L., Dempsey, R.J. \& Karsch, F.J. (1983) Pineal melatonin drives the reproductive response to daylength in the ewe. Endocrinology 113, 2276-2283.

Bubenik, G.A. \& Smith, P.S. (1987) Circadian and circannual rhythm of melatonin in plasma in adult male white tailed deer the effect of oral administration of melatonin. J. exp. Zool. 241, 81-89.

Fennessy, P.F., Suttie, J.M., Crosbie, S.F., Corson, I.D., Elgar, H.J. \& Lapwood, K.R. (1988) Plasma LH and testosterone responses to $\mathrm{GnRH}$ in adult red deer stags during the annual antler cycle. $J$. Endocr. 117, $35-41$.

Fisher, M.W., Fennessy, P.F. \& Milne, J.D. (1988) Effects of melatonin on seasonal physiology of red deer. Proc. N.Z. Soc. Anim. Prod. 48, 113-116.

Jaczewski, Z. (1954) The effect of changes in length of daylight on the growth of antlers in the deer (Cervus elaphus L.). Folia biol., Praha 2, 133-143.
Karsch, F.J. \& Wayne, N.L. (1988) Interplay of endogenous rhythms and environmental cues in organizing the seasonal reproductive cycle of the ewe. Proc. 1/th Int. Congr. Anim. Reprod. \& AI, Dublin, pp. 221-227.

Kay, R.N.B. \& Ryder, M.L. (1978) Coat growth in red deer (Cervus elaphus) exposed to a day-length cycle of six months duration. J. Zool., Lond. 185, 505-510.

Kennaway, D.J., Gilmore, T.A. \& Seamark, R.F. (1982) Effects of melatonin implants on the circadian rhythm of plasma melatonin and prolactin in sheep. Endocrinology 110, 2186-2188.

Lincoln, G.A. (1971) The seasonal reproductive changes in the red deer stag (Cervus elaphus). J. Zool., Lond. 163, $105-123$.

Lincoln, G.A. (1985) Seasonal breeding in deer. In Biology of Deer Production, pp. 165-179. Royal Society of New Zealand, Wellington.

Lincoln, G.A. \& Ebling, F.J.P. (1985) Effect of constant release implants of melatonin on seasonal cycles in reproduction, prolactin secretion and moulting in rams. J. Reprod. Fert. 73, 241-253.

Lincoln, G.A., Fraser, H.M. \& Fletcher, T.J. (1984) Induction of early rutting in male red deer (Cervus elaphus) by melatonin and its dependence on LHRH. J. Reprod. Fert. 72, 339-343. 
Pollock, A.M. (1975) Seasonal changes in appetite and sexual condition in red deer stags maintained on a six-month photoperiod. J. Physiol., Lond. 244, 95-96P, abstr.

Ryder, M.L. \& Kay, R.N.B. (1973) Structure of and seasonal change in the coat of red deer (Cervus elaphus). J. Zool., Lond. 170, 69-77.

Suttie, J.M., Corson, I.D. \& Fennessy, P.F. (1984) Voluntary intake, testis development and antler growth patterns of male red deer under a manipulated photoperiod. Proc. N.Z. Soc. Anim. Prod. 44, 167-170.

Webster, J.R. \& Barrell, G.K. (1985) Advancement of reproductive activity, seasonal reduction in prolactin secretion and seasonal pelage changes in pubertal red deer hinds (Cervus elaphus) subjected to artificially shortened daily photoperiod or daily melatonin treatments. J. Reprod. Fert. 73, 255-260.

Received 20 March 1990 